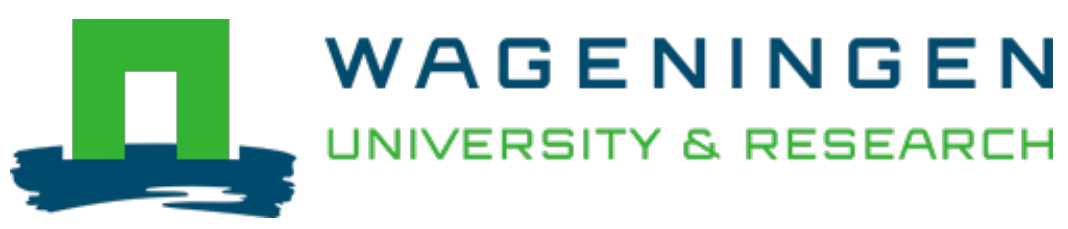

\title{
Characterizing variations of greenspace landscapes in relation to neighborhood characteristics in urban residential area of Beijing, China
}

\author{
Landscape Ecology \\ Yan, Jingli; Zhou, Weiqi; Zheng, Zhong; Wang, Jia; Tian, Yunyu \\ https://doi.org/10.1007/s10980-019-00943-3
}

This publication is made publicly available in the institutional repository of Wageningen University and Research, under the terms of article $25 \mathrm{fa}$ of the Dutch Copyright Act, also known as the Amendment Taverne. This has been done with explicit consent by the author.

Article 25 fa states that the author of a short scientific work funded either wholly or partially by Dutch public funds is entitled to make that work publicly available for no consideration following a reasonable period of time after the work was first published, provided that clear reference is made to the source of the first publication of the work.

This publication is distributed under The Association of Universities in the Netherlands (VSNU) 'Article $25 \mathrm{fa}$ implementation' project. In this project research outputs of researchers employed by Dutch Universities that comply with the legal requirements of Article $25 \mathrm{fa}$ of the Dutch Copyright Act are distributed online and free of cost or other barriers in institutional repositories. Research outputs are distributed six months after their first online publication in the original published version and with proper attribution to the source of the original publication.

You are permitted to download and use the publication for personal purposes. All rights remain with the author(s) and / or copyright owner(s) of this work. Any use of the publication or parts of it other than authorised under article $25 \mathrm{fa}$ of the Dutch Copyright act is prohibited. Wageningen University \& Research and the author(s) of this publication shall not be held responsible or liable for any damages resulting from your (re)use of this publication.

For questions regarding the public availability of this publication please contact openscience.library@wur.nl 


\title{
Characterizing variations of greenspace landscapes in relation to neighborhood characteristics in urban residential area of Beijing, China
}

\author{
Jingli Yan $\cdot$ Weiqi Zhou $\cdot$ Zhong Zheng $\cdot$ Jia Wang $\cdot$ Yunyu Tian
}

Received: 28 June 2019/Accepted: 25 November 2019/Published online: 3 December 2019

(C) Springer Nature B.V. 2019

\begin{abstract}
Content Urban residential greenspace is considerably contributing to sustainable cities and residents' well-being. An increasing number of studies have examined the greenspace inequalities and species biodiversity in relation to social theories in private gardens of US and European cities; however, much less studied is landscape configurations, especially in rapidly urbanizing cities like Beijing, China.

Objectives To demonstrate the fine-scale landscape variations of residential greenspace in Beijing urban area, and also to examine the main predictors of neighborhood characteristics on greenspace landscapes.

Methods A greenmap of Beijing urban area was first derived from Pleiades-1A images, then residential greenspace landscapes were examined using six
\end{abstract}

Electronic supplementary material The online version of this article (https://doi.org/10.1007/s10980-019-00943-3) contains supplementary material, which is available to authorized users.

J. Yan · W. Zhou ( $($ ) $\cdot$ Z. Zheng · J. Wang $\cdot$ Y. Tian State Key Laboratory of Urban and Regional Ecology, Research Center for Eco-Environmental Sciences, Chinese Academy of Sciences, Shuangqing Road 18, Haidian District, Beijing 100085, China

e-mail: wzhou@rcees.ac.cn

J. Yan - W. Zhou $\cdot$ Z. Zheng $\cdot$ J. Wang $\cdot$ Y. Tian University of Chinese Academy of Sciences, Beijing 100049, China landscape metrics, finally correlation and multiple regression analysis were performed to explore the relationships of greenspace landscape metrics and neighborhood characteristics.

Results The neighborhood characteristics are affecting residential greenspace of Beijing city. The neighborhoods with more and fragmented green coverage, complex patch shape and higher patch size variations are generally more aged, more distant to the city center and have lower plot-ratios. A distance of one additional kilometer to city center increases the vegetation coverage by $0.16 \%$ and the mean patch size by $10.17 \mathrm{~m}^{2}$. A neighborhood of one year older increases the patch density by 8.69. Moreover, one unit higher plot-ratio reduces the edge density by 5.66 , and the patch size coefficient of variation by 7.03.

Conclusions Urban structure affects residential landscapes, and greenspace management approaches applied to optimize urban human well-being should integrate urban/landscape ecology with residential architecture.

Keywords Residential greenspace $\cdot$ Landscape configuration · Urban neighborhoods · Landscape predictors 


\section{Introduction}

Residential greenspace not only provides numerous ecosystem services (Pickett et al. 2011) but also serves as crucial refuges for residents' health (Jenerette et al. 2016). For example, both visually and aesthetically greenspace encourages residents to participate in more physical outdoor activities (Dahlkvist et al. 2016), leading to a lower occurrence of obesity (Villeneuve et al. 2018) and a lower number of chronic diseases (Gascon et al. 2016). In addition, urban residential areas would be most potential places to increase urban greenspace as they take up a large proportion of urban lands (Richards et al. 1984; Loram et al. 2007; Lin et al. 2015). The urban residential area becomes even more crucial in the last decade as increasing number of cities have set ambitious goals of increasing tree canopy cover, such as, several US cities have pledged to add one million trees to existing urban forests (Pincetl 2010).

Urban residential greenspace is increasingly important to residents in terms of accessibility and instant benefits, however the private residential greenspace was much less studied than public greenspace. In the last decade, increasing interests have been focused on "green justice" in urban private parcels/gardens, and explained the inequalities using socioeconomic theories (Hope et al. 2003; Nassauer et al. 2009; Kabisch and Haase 2014; Locke et al. 2018; Fan et al. 2019; Ossola et al. 2019). For instance, neighborhoods with lower incomes and less-educated residents tended to be less vegetated in Harford, Connecticut, US (Wu et al. 2015; Li et al. 2015). High income, low density neighborhoods have the highest vegetation cover in Los Angeles, California, US (Clarke et al. 2013). Citizens living in internal cities had a stronger desire for greenness but consumed less greenspace cover per capita than those living in external urban areas (Kirkpatrick et al. 2012). Considerable dissimilarities in green coverage exist between different immigrant statuses and ages in Berlin (Kabisch and Haase 2014). Comparing to US and European cities, rapid developing cities in other regions of the world still had very limited number of studies conducted in urban neighborhoods (Gupta et al. 2012; Tian et al. 2014a, b; Jim and Zhang 2015; Zheng et al. 2017). Moreover, spatial arrangements and configurations of residential greenspace were far less examined in existing studies. However, landscape configurations also contribute to reduce urban heat (Jiao et al. 2017; Yan et al. 2019) and differentiate heterogeneous residential landscapes (Gupta et al. 2012; Tian et al. 2014a, b). For instance, well-designed greenspace decreases the crime rate by drawing more people to be outdoors, leading to an informal surveillance system and an increased sense of safety (Kuo and Sullivan 2001). House buyers in Hong Kong and Shenzhen were willing to pay approximately $17 \%$ more for the appearance of residential gardens (Jim and Chen 2010). Building on existing evidence, we selected the rapidly urbanizing city of Beijing, China as a case study, and we proposed two questions: (1) what are the variations of landscape configurations in urban residential greenspace? (2) what are the main predictors for the variations in residential greenspace landscapes?

Existing studies on Beijing urban greenspace landscapes were mostly carried on large scales to detect the land use/cover dynamics associated with rapid urbanization (Wu et al. 2006; He et al. 2011; Zhang et al. 2016) using medium spatial resolution images (Tian et al. 2014a, b; Wu et al. 2015; Li et al. 2015; Huang et al. 2017). The built-up area of Beijing had spread from $109 \mathrm{~km}^{2}$ of 1949 to $1446 \mathrm{~km}^{2}$ of 2017 (National Bureau of Statistics of China 2018). In addition, $1402 \mathrm{~km}^{2}$ of land was devegetated and $1090 \mathrm{~km}^{2}$ of land was revegetated in Beijing from 1985 to 2015 (Huang et al. 2017). More specific, the urban expansion was mainly concentrated in 4th ring road to 6th ring road in the northwest and southeast directions in the period from 1970 to 2015 (Zhang et al. 2016; Liu et al. 2017), and the annual growth rate of Beijing urban area was 36.45-99.48 km $\mathrm{km}^{2}$ (Wu et al. 2015 , b), and the annual decreasing rate of total greenspace was $47 \mathrm{~km}^{2}$ from 1992 to 2004 (Wu et al. 2006), leading to decreased greenspace and a more fragmented landscape in the fringe area (Zhang et al. 2015). On the contrary, Tian et al. (2014a, 2014b) revealed a significant increase in urban forest from 1990 to 2010 . Increased urban greenspace in old city districts by annual rate of $1.51 \%$ from 1990 to 2010 were suggested by Tian et al. (2014a, b). Qian et al. (2015a) also observed that the greenspace coverage sharply increased from the urban core to the fringe area of 4th-5th ring road. Those urban green dynamics associated with urbanization would affect the availability and landscapes of urban residential greenspace, as the urban housing practice and urbanization were developed in a coordinated way. 
However, a general understanding on landscape dynamics at regional or city level with medium spatial resolution remote sensing images may fail to reveal heterogeneous and fragmented urban areas, as scale is a central issue that influences spatial analyses and associations among landscape patterns (Turner et al. 1989; Benson and MacKenzie 1995). For more intensely intra-urban areas, a higher spatial resolution remote sensing image is necessary for detecting urban greenspace variation as suggested by Qian et al. (2015a, b). Similar results also were revealed by Zhou et al. (2018) that many highly fragmented and small sized green patches ("invisible" changes) only can be detected by fine-scale remote sensing images. Meanwhile, landscape metrics maintain significant potentials for exploring urban landscape characteristics $(\mathrm{Wu}$ 2007). However, several related indices should be jointly considered but redundant information should be abridged for a comprehensive explanation of urban landscape and ecological quality ( $\mathrm{Li}$ and $\mathrm{Wu} 2004$ ). For example, commonly used landscape metrics, e.g. patch density, mean patch size, edge density, and fractal dimension, are reliable and efficient in delineating urban landscapes as suggested by existing studies (Wu 2004, 2007; Kong and Nakagoski 2006; Weng et al. 2008; Zhou et al. 2011, 2017; Kong et al. 2014; Qian et al. 2015b). Moreover, Li et al. (2013) indicated the higher spatial resolution remote sensing images, instead of medium spatial resolution images, could more accurately quantify the urban greenspace landscapes, after comparing the landscape metrics calculated by three different spatial resolution images $(2.4 \mathrm{~m}, 10 \mathrm{~m}, 30 \mathrm{~m})$ in Beijing urban area.

With respect to predictors for urban residential greenspace, Grove et al. (2006) concluded them into three main social theories; social stratification $(\mathrm{Wu}$ et al. 2015; Li et al. 2015), lifestyle behavior (Gill et al. 2008) and population density (Smith et al. 2005; Cook et al. 2012). However, the empirical results in US and European cities may not directly transfer to other parts of world, such as Chinese cities, due to differences in both urban morphology and social ecological systems. On one hand, Chinese cities were originally rooted in a strong ideology of breaking down social and spatial barriers that are delineated as classes in nonsocialist countries (Leaf 1995). Since 1990s, numerous houses have been added to Beijing housing stock to accommodate "civil immigrants" (Wang 2001). Only in 2005, the area of newly completed houses was
$2.8 \times 10^{7} \mathrm{~m}^{2}$, accounting for $13.1 \%$ of the existing housing stock (Beijing Municipal Bureau of Statistics 2006). Therefore, considering the ongoing rapid urbanization and only 20 years after replacing welfare housing system with commercial housing market in 1998, Chinese cities need more time to develop a solid social-ecological system and a mature housing market as US and European cities had done. On the other hand, in addition to social theories, "neighborhood noms" significantly affected homeowners' preference for their own yards (Nassauer et al. 2009). For instance, housing age was significantly associated with green coverage (Zheng et al. 2017). Housing parcels that are more distant from the urban core have larger green yards (Haase et al. 2019), which is driven in part by preferences for landscape and open space amenities (Fernandez et al. 2005), and low density neighborhoods have the highest vegetation cover (Clarke et al. 2013). Architectural style reflects the socioeconomic status of residents, as they would landscape their yards with more greenspace to highlight the prestige of their neighborhoods (Nasar 1989; Ossola et al. 2019).

Relying on the existing evidence mainly from US and European cities that the residential landscape evolves over time in terms of social theories, and the fact that Beijing have adopted a different urbanization mode and urban housing structure. Here we hypothesized neighborhood characteristics, such as house age, house location, architectural style, and even historical legacies (Larson et al. 2017), are more related to the greenspace landscapes of Beijing residential area. Fine-scale urban green map $(0.5 \mathrm{~m})$ were produced and five attributive characteristics of 3121 neighborhoods in Beijing urban area were collected to investigate: (1) the spatial and quantitative distribution of Beijing urban neighborhoods; (2) landscape variations, both coverage and configurations, of urban residential greenspace; and (3) the associated predictors of neighborhood characteristics to residential greenspace landscapes. Our examinations in rapidly developing Beijing enriched the global databases of urban residential landscape characteristics, which would support urban planning and design links to landscape ecology. 


\section{Data source and processing}

Study area

Beijing's five-ring area is one of the most densely populated areas in the world, and nearly half (49\%, 10.55 million) of Beijing's population lives in the fivering area (Beijing Municipal Bureau of Statistics 2016). A total of 2523 urban residential neighborhoods were delineated in 2010 (Zheng et al. 2017); these residential neighborhoods were spatially heterogeneous and diverse in terms of building age, architectural style, and greenspace landscape. The external expansion and internal redevelopment of Beijing urban area have resulted in a significant amount of greenspace being converted into built-up areas. The greenspace coverage of prefectural Beijing city was $47.4 \%$ and $15.9 \mathrm{~m}^{2}$ of public vegetation per capita in 2015; however, the coverage of the five-ring area was only 30.8\% (Beijing Municipal Bureau of Statistics 2016). In regard to urban housing development, Beijing differs from other major Chinese cities, e.g., Shanghai and Guangzhou, due to its different development strategies that are congruous with its historic roots. Since the "reform and opening up" in 1978, numerous houses have continually been added to the housing stock due to loose land policies in 1988, demolition and redevelopment campaign in inner cities in 1990s, and the announcement of a commercial housing market in 1998 (Zheng and Kahn 2008). The total building floor space of Beijing housing stock increased from $1.02 \times 10^{10} \mathrm{~m}^{2}$ of 1980 to $6.36 \times 10^{10} \mathrm{~m}^{2}$ of 2015 at an average growth rate of $5.4 \%$ (Huo et al. 2019) to accommodate the sharply increased population. After 30 years of rapid urbanization and housing development, the neighborhoods within the Beijing five-ring area are characterized by compactness and heterogeneity.

\section{Beijing urban greenmap}

The greenmap of the Beijing five-ring area was derived from Pleiades-1A satellite images acquired on June 5, 2015. Pleiades-1A is capable of acquiring high-resolution stereo images in just one pass over large areas (up to $10^{6} \mathrm{~km}^{2}$ ), and locating an ground object within $1 \mathrm{~m}$ of its physical location. The Pleiades-1A satellite sensor has a spatial resolution of 0.5 meters for panchromatic $(480-830 \mathrm{~nm})$ and $2 \mathrm{~m}$ for multispectral images (blue: $430-550 \mathrm{~nm}$; green: 490-610 nm; red: $600-720 \mathrm{~nm}$; and near infrared: $750-950 \mathrm{~nm}$ ). The imageries we used were already preprocessed and orthographic calibrated standard products. Then Gram-Schmidt (GS) algorithm was applied to pan-sharpen the images using ENVI 5.3 because the GS method can produce better spatial details and maintain the original spectral quality of multi-band imagery (Yuhendra et al. 2012). Finally the geometric correction also conducted in ENVI 5.3 with Googlemaps as reference map, and controlling the RMSE $<0.5$.

Object-Based Image Analysis (OBIA, Benz et al. 2004; Blaschke 2010) was selected as OBIA not only can delineate more accurate characteristics of ground objects, and also can introduce more spectral and spatial features to identify ground objects than pixelbased approach, especially for higher spatial resolution images (Chen et al. 2012; Yan et al. 2018). The multi-resolution segmentation (MRS) is the basis and directly affects the accuracy of OBIA classification. There are three key parameters (scale, shape, compactness) that can be modified to control segmentation results. Larger "scale" parameters result in "oversegmentation" (one segment comprises more than on land cover type), while a small "scale" leads to the "under-segmentation". A relatively small value is generally recommended for shape, so that more weight can be set on color/spectral information. The parameter compactness determines the compactness or smoothness of the objects (eCognition Developer reference book). Therefore, we set the parameters ( scale $=25$, shape $/$ compactness $=0.2 / 0.5)$ for our segmentation in eCognition Developer 9.0 (Trimble, http://www.ecognition.com/suite/ecognition-developer) according to visual inspection. After segmentation, the segmented objects with NDVI (Near Infrared-Red/Near Infrared + Red) value $>0.18$ were extracted as greenspace, and some misclassified objects (colorful roofs and artificial soccer fields) were removed from greenspace using mean value of blue band $(>420)$. The overall accuracy of the greenmap was $98 \%$, with a Kappa coefficient of 0.96 . The total area of greenspace within the Beijing five-ring area was $205.79 \mathrm{~km}^{2}$, and the area percentage was $30.82 \%$ (Fig. 1). 


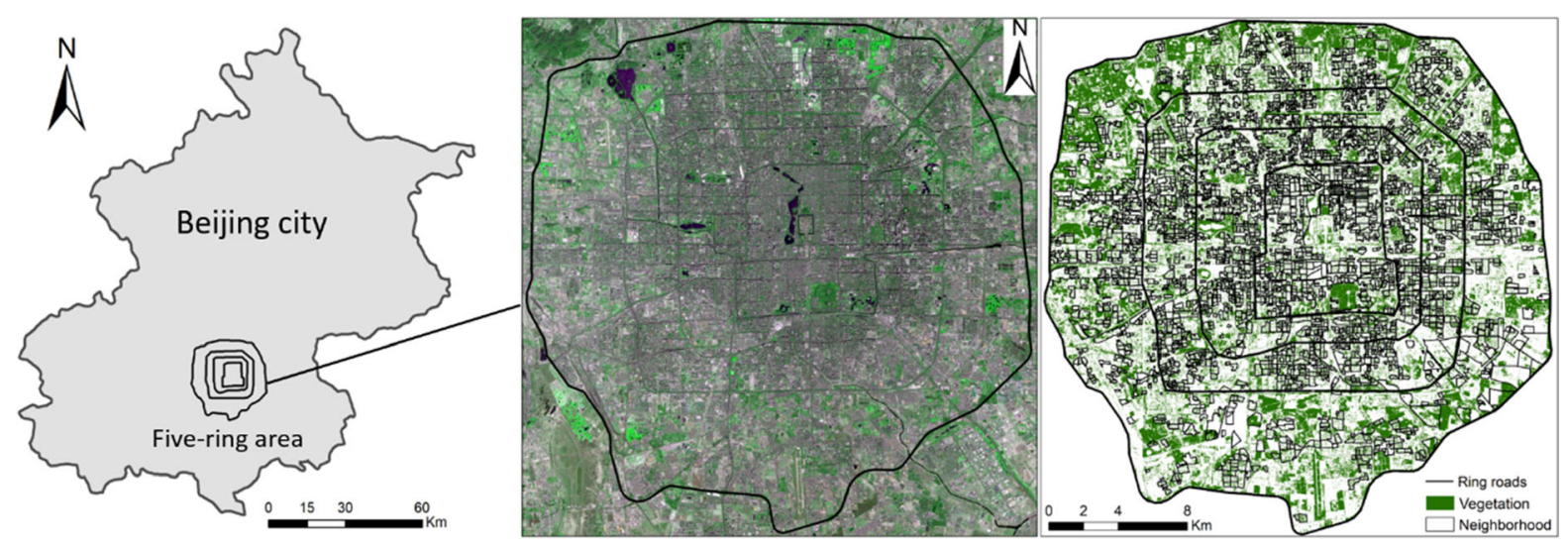

Fig. 1 The greenmap of Beijing five-ring area from a Pleiades-1A image (true color) in 2015

Urban residential neighborhoods

The neighborhood boundaries were developed based on the methods of Zheng et al. (2017), in which 2523 neighborhoods were visually delineated with a reference map of GeoEye images within the five-ring area in 2010. The new version was developed in 2014 by delineating newly built neighborhoods and removing demolished areas. During the delineation, several rules were followed to improve the boundary accuracy: (1) Integrality. Urban neighborhoods in Beijing city are usually walled or fenced. A neighborhood is a complex of buildings and basic living infrastructures, so all non-residential buildings like activity center, community school, neighborhood gardens and parking lots served for the neighborhood were included. (2) Homogeneity. For a neighborhood consisting of different architectural style (e.g., multi-rises and high-rises) or constructed in different decades (e.g., 1990s and 2000s), we treat them as different neighborhoods. (3) Flexibility. Since Hu-tongs are unique structures and different from common urban neighborhoods, we dealt with them in a different way. Hutong neighborhoods were outlined by roads, and the roads used for dividing Hu-tongs were at least a fourlane road. Finally, 3121 neighborhoods were obtained within the five-ring area of Beijing by the end of 2014 .

Five neighborhood characteristics (Table 1), neighborhood age, unit price, plot ratio, building type and neighborhood location, were collected during the delineation to represent neighborhoods considering accessibility and reliability. The neighborhood characteristics were copied from Chinese real estate trading website (Fang.com, http://bj.fang.com), which had higher data integrity and more timely information. For few neighborhoods (37), mainly are Hu-tongs, that haven't be included in the Fang.com, we collected the information from another real estate trading website (Lianjia, https://bj.lianjia.com) or asked the residents living in the specific neighborhoods. We used the rebuilt or refurnished year as the built year for neighborhoods that had been rebuilt or considerably refurnished. In addition, building height and the distance to the city center of a neighborhood were used as auxiliary datasets. We calculated the average building height of a neighborhood based on Beijing urban building footprints and heights collected from Baidu ${ }^{\mathrm{TM}}$ map (Zheng et al. 2017). The Euclidean distance to the city center (Tian'anmen square) from a neighborhood was calculated in ArcGIS 10.4. The numerical variables of average building height and distance to the city center were only analyzed in statistical analyses ("Statistical analysis" section) to replace the class variables of neighborhood type and neighborhood location. This replacement occurred as the variable type are more consistent with others in statistical analyses.

\section{Analysis}

Categorizing the urban neighborhoods

We categorized the neighborhoods into groups in terms of five neighborhood characteristics (Table 2). The neighborhood age was calculated based on the number of years from a neighborhood was completely built to the year of 2014. Five neighborhood building 
Table 1 The selected characteristics of the neighborhoods

\begin{tabular}{ll}
\hline Name & Definition \\
\hline Age & The number of years of a neighborhood since the construction year to 2014 (years) \\
Unit price & The unit price of a neighborhood in December $2014\left(10^{4} \mathrm{CNY} / \mathrm{m}^{2}\right)$ \\
Plot ratio & The ratio of the total area of buildings built on the ground to the size of the floor area, $>0$ \\
Type & A mixed metric combining building height and architectural style, which was replaced by average height in \\
section "Statistical analysis" & The location of a neighborhood based on its central point, axes, and ring roads of the Beijing urban area, \\
wocation & The average of all building heights in a neighborhood (m), only used in section "Statistical analysis" \\
Average height & $\begin{array}{l}\text { The Euclidean distance of a neighborhood's geometric center to the center of Tian'anmen square (km), only } \\
\text { used in section "Statistical analysis" } \\
\text { center }\end{array}$
\end{tabular}

Table 2 The categories of neighborhood characteristics

\begin{tabular}{llllll}
\hline \multicolumn{1}{c}{ Age } & Unit Price & Neighborhood type & Plot ratio & Location \\
\hline Class & $0-9$ & $1-3$ & Villa (VI) & $0-1$ & Internal North-East (INE) \\
& $10-16$ & $3-5$ & Low rise (LR) & $1-2$ & Internal North-West (INW) \\
$17-26$ & $5-7$ & Multiple rise (MR) & $2-3$ & Internal South-East (ISE) \\
$27-35$ & $7-9$ & Middle high rise (MHR) & $3-4$ & Internal South-West (ISW) \\
$36-$ & $9-$ & Slab-type high rise (SHR) & $4-5$ & External North-East (ENE) \\
Until 2014 & $\times 10^{4} \mathrm{CNY} / \mathrm{m}^{2 a}$ & Tower-type high rise (THR) & $5-$ & External North-West (ENW) \\
& & Based on average height and architectural style & No unit & External South-East (ESE) \\
& & & & External South-West (ESW) \\
\hline
\end{tabular}

${ }^{\mathrm{a}}$ The official exchange rate was 6.2 CNY per USD on 31 December 2014. Integers were included in the former classes for the unit price and plot ratio

periods (before 1978; 1979-1987; 1988-1997; 1998-2004; after 2005) were divided according to major policy changes in the Beijing urban housing market (Wang 2001). For example, China launched housing reform in 1979, opened national and collective lands to housing developers in 1988, replaced welfare housing with commercial housing in 1998, instituted macro-regulation and control to the housing market in 2005.

The unit price of a neighborhood was the price per square meter in Chinese Yuan $\left(\mathrm{CNY} / \mathrm{m}^{2}\right)$ in December 2014. The average unit price was $46,452 \mathrm{CNY} / \mathrm{m}^{2}$, with the lowest value of $12,871 \mathrm{CNY} / \mathrm{m}^{2}$ and the highest value of $144,159 \mathrm{CNY} / \mathrm{m}^{2}$ (http://bj.fang. com). Since there were far fewer neighborhoods with a unit price $>9 \times 10^{4} \mathrm{CNY} / \mathrm{m}^{2}$ than those in other unit price ranges, we included these neighborhoods in one group to finally have five groups with an interval of $2 \times 10^{4} \mathrm{CNY} / \mathrm{m}^{2}$.

Neighborhood type was an integrated characteristic that reflects both building height and architectural style. Our neighborhood types were modified from the national standard of the "General rule for architectural design of civil buildings (GB/T50352-2005)". First, we merged the bungalow and low-rise designations in the national standard into low-rise, and high-rise and super-high-rise into high-rise since there were too few to stand out as a single class. Then, some classes in the national standard were further subdivided. We separated villas from low-rises as villas are distinct from other low-rise buildings in architectural style. Highrises were subdivided into slab-type high-rises and tower-type high-rises. For a few neighborhoods consisting of mixed architectural styles, we used the 
quantitatively dominant style. In total, six neighborhood types were classified (Table 2; Fig. 2).

The plot ratio is the ratio of a building's total floor area (gross floor area) to the size of the land upon which it is built. The plot ratio represents the number of people that a building/neighborhood can hold, it directly limits the building density and urban density. Plot ratio of a neighborhood was regulated by the national standard of "Standard measurement for construction area of building (GB/T50353-2005)". In general, the plot ratio of villas was $<1$, multiplerises usually was $<3$, and high-rises usually was $<5$. Neighborhoods with plot ratios $>5$ were merged into one group due to their small quantity. In total, we had six plot ratio groups with an interval of 1 .

For neighborhood location, we selected two urban central axes (east-west and north-south directions) and two ring roads (3rd and 5th ring roads) to divide the five-ring area into eight sections (Fig. 3). The division was based on the urbanization pattern (Zhang et al. 2015; Yu and Zhou 2017) and housing development (Leaf 1995; Wang 2001) in the Beijing urban area. The urban area originally expanded from the three-ring area in 1970s to the five-ring area in 2000s, with the northern sections developing faster and the southwestern sections lagging behind.

\section{Landscape analysis}

We computed six landscape metrics (Table 3) for each neighborhood to represent the residential greenspace landscapes through delineating neighborhood boundaries and producing a greenmap based on Pleiades-1A image. Coverage is the actual percentage area of greenspace in a neighborhood (area of total green space/area of the neighborhood), and configuration is the placement, distribution, patch shape, patch size, variations of patches, etc., of the greenspace, usually can be represented by landscape metrics. These selected metrics have commonly been observed in previous studies (Wu 2007; Li et al. 2013; Kong et al. 2014; Tian et al. 2014a, b; Zhou et al. 2017) and could
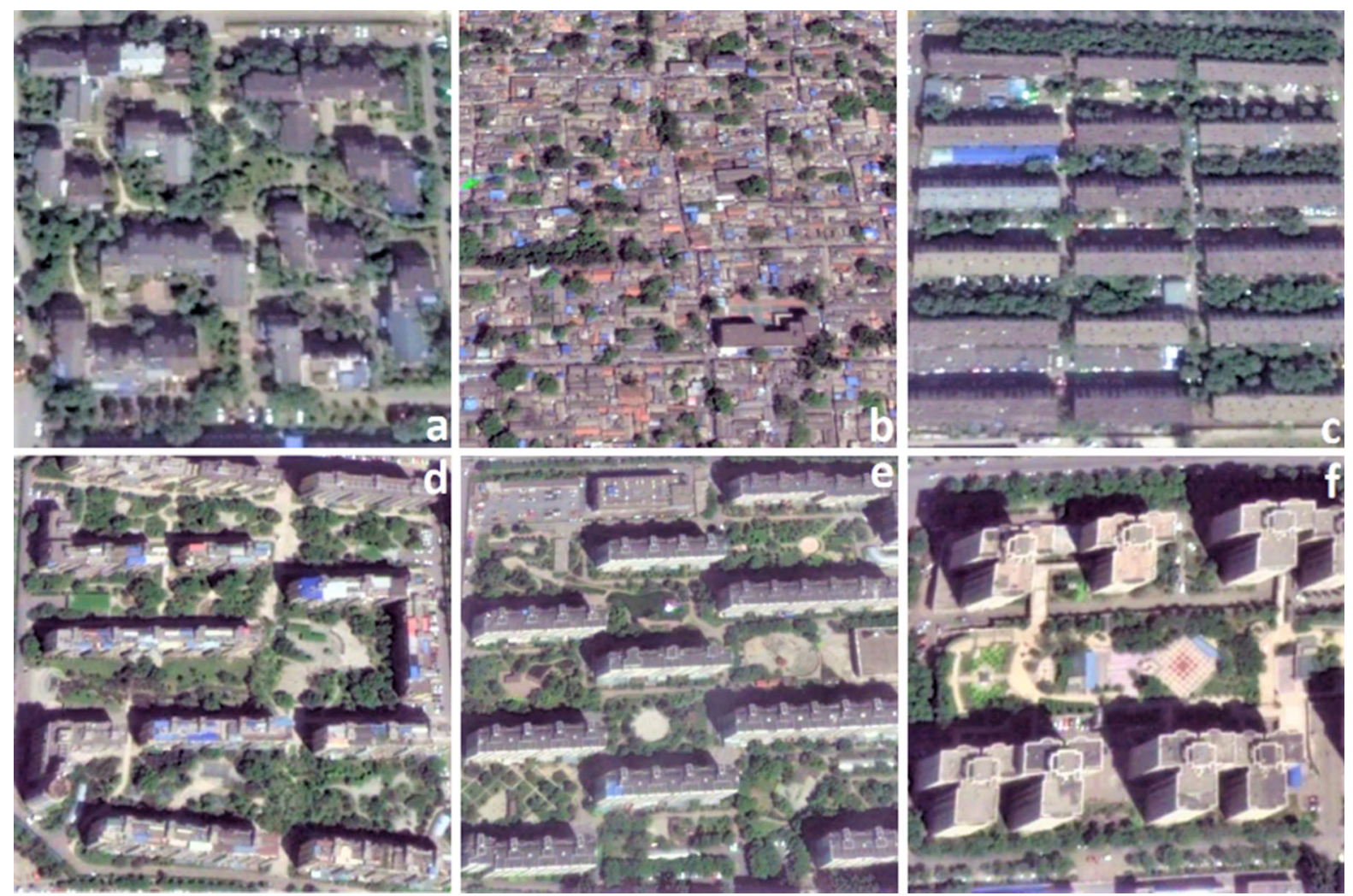

Fig. 2 The characteristics of neighborhood types, a villa; b low rise (Hu-tong); c multiple rise; d middle high rise; e slab-type high rise; f tower-type high rise 


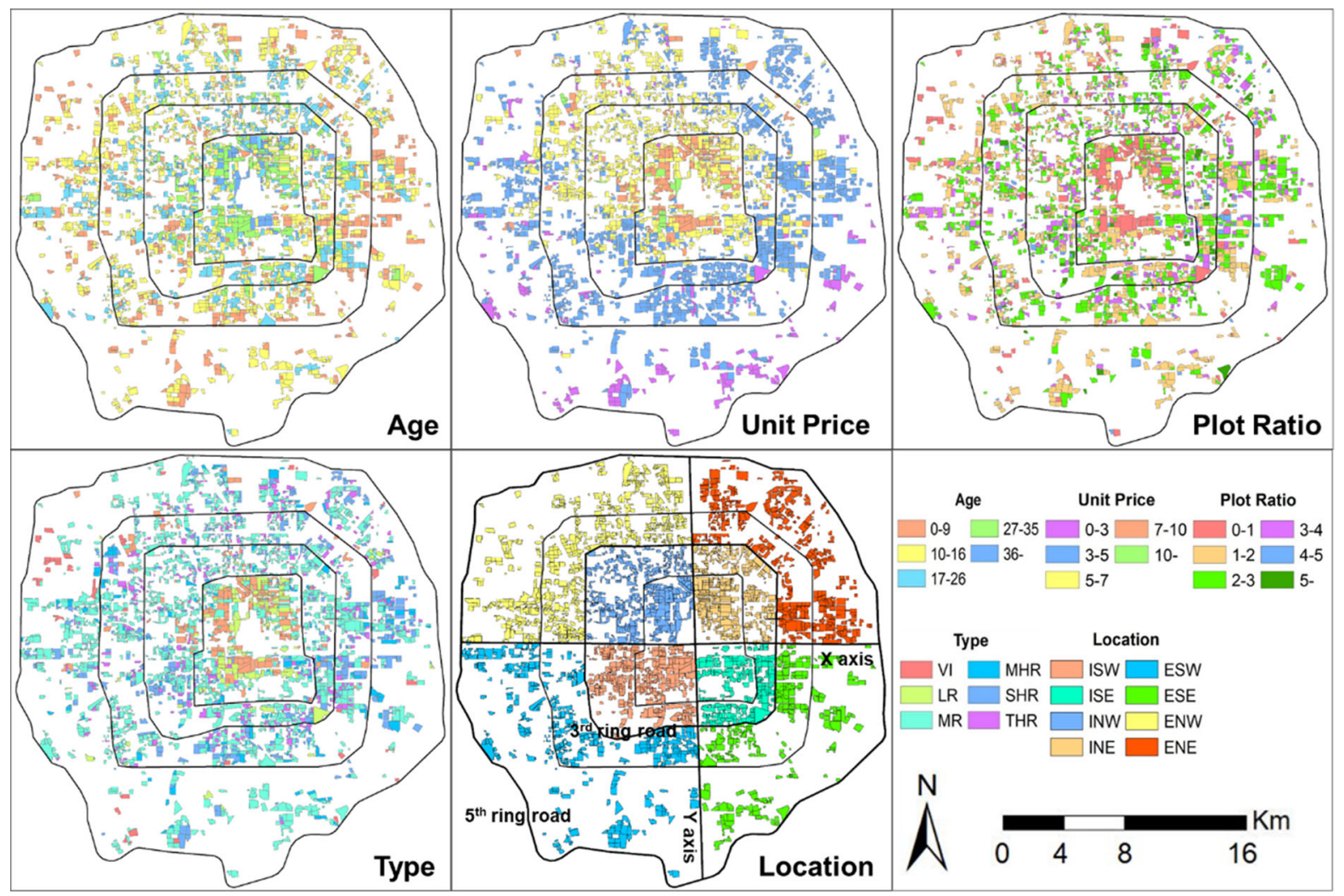

Fig. 3 The spatial distribution of Beijing urban neighborhoods

Table 3 Summary of the landscape metrics used in the study (Wu 2007)

\begin{tabular}{|c|c|c|}
\hline Metric & Description & Equations \\
\hline Vegetation coverage (VC) & $\begin{array}{l}\text { The sum of the area of vegetation patches divided by the total landscape area } \\
(\%)\end{array}$ & $V C=\frac{\sum_{j=1}^{n} a_{i j}}{A} * 100$ \\
\hline Edge density (ED) & $\begin{array}{l}\text { The sum of the length of all vegetation edge segments divided by the total } \\
\text { landscape area }\left(\mathrm{km}^{2}\right)\end{array}$ & $E D=\frac{\sum_{j=1}^{m} e_{i j}}{A} * 10^{6}$ \\
\hline $\begin{array}{l}\text { Area-weighted mean fractal } \\
\text { dimension (AWMFD) }\end{array}$ & $\begin{array}{l}\text { The sum, across all patches of the corresponding patch type, of } 2 \\
\text { times the logarithm of the patch perimeter divided by the logarithm } \\
\text { of the patch area multiplied by the patch area divided by the total } \\
\text { class area, 1-2 (no unit) }\end{array}$ & $\mathrm{FD}=\frac{2 * \ln \mathrm{p}_{\mathrm{ij}}}{\ln \mathrm{a}_{\mathrm{ij}}}$ \\
\hline Patch density (PD) & $\begin{array}{l}\text { The number of patches of the corresponding patch type divided by } \\
\text { the total landscape area }\left(\mathrm{km}^{2}\right)\end{array}$ & $\mathrm{PD}=\frac{\mathrm{n}_{\mathrm{i}}}{\mathrm{A}} * 10^{6}$ \\
\hline Mean patch size (MPS) & $\begin{array}{l}\text { The sum of the areas of all patches of the corresponding patch type divided by } \\
\text { the number of patches of the same type }\left(\mathrm{m}^{2}\right)\end{array}$ & MPS $=\frac{\sum_{j=1}^{n} a_{i j}}{n_{i}}$ \\
\hline $\begin{array}{l}\text { Patch size coefficient of } \\
\text { variation }(\mathrm{PSCoV})\end{array}$ & $\begin{array}{l}\text { The standard deviation of the vegetation patch size divided by the mean patch } \\
\text { size of the corresponding patch type (no unit) }\end{array}$ & $\mathrm{PSCov}=\frac{\mathrm{MPS}}{\mathrm{SSD}}$ \\
\hline
\end{tabular}

$\overline{a_{i j}}$ area $\left(\mathrm{m}^{2}\right)$ of patch $\mathrm{ij}, p_{i j}$ perimeter $(\mathrm{m})$ of patch $\mathrm{ij}, e_{i j}$ edge $(\mathrm{m})$ of patch $\mathrm{ij}, n_{i}$ number of patches in the landscape of patch class $\mathrm{i}$, $A$ total landscape area $\left(\mathrm{m}^{2}\right)$, and $S S D$ sample standard deviation 
comprehensively reflect landscape composition and configuration. We first overlapped the neighborhood boundaries and greenmap to create vegetation patches within neighborhoods, and then only vegetation patches were kept to save computational time. Then the selected landscape metrics were calculated for all neighborhoods in the patch analyst for ArcGIS (http:// www.cnfer.on.ca/sep) using neighborhoods as the analytical unit. Then every neighborhood outlined had values of different landscape metrics listed in Table 3 . Finally, the landscape metrics were organized in terms of neighborhood categories, as shown in Table 2.

\section{Statistical analysis}

We used correlation analysis and multiple regression analysis to examine the relationships between urban residential greenspace and selected landscape characteristics. First correlation analysis were used to assess the strength of association between each residential greenspace landscape metric and each neighborhood characteristics, and then multiple regression models were built to explore both combined and single effects of various neighborhood characteristics on greenspace landscape metrics. All 3121 urban neighborhoods were included in the statistical analyses. To promote consistency in the statistical analysis, the neighborhood characteristics of neighborhood type and location, which are categorical variables, were represented by continuous variables, i.e., the average building height and distance to the city center of the neighborhoods, respectively (Table 1). Spearman correlation was then selected because the datasets had nonGaussian distributions. For the correlation analysis, we also adjusted resulted p-values using the Benjamini-Hochberg method (Benjamini and Hochberg 1995) to reduce possible high family-wise error rate, as it's a powerful tool to avoid false positives errors by decreasing the false discovery rate accordingly to their ranking. After correlation analysis, variables have been logarithmically converted and passed the collinearity test before running the multiple regression analysis. All neighborhood characteristics were input as independent variables, and the landscape indices were used as dependent variables; all variables were entered and considered to evaluate how neighborhood characteristics influence residential greenspace landscapes. When choosing the best fitting model for the relationships, the models were evaluated and identified using the Akaike information criterion (AIC) value (Akaike 1974), where the model with the smallest AIC value was chosen as the best predictive model. The AIC value was calculated as follows:

$\mathrm{AIC}=\mathrm{n} * \ln (\mathrm{RSS} / \mathrm{n})+2 \mathrm{p}$

where RSS is the residual sum of squares between each model prediction and the observation, $n$ is the number of observations, and $p$ is the total number of parameters in the model. In all cases, analyses were primarily directed to testing hypothesized controls of neighborhood characteristics to residential landscapes rather than generate predictive models.

\section{Results}

Descriptive analysis of Beijing urban neighborhoods

Within the 5th ring road, Beijing had 3121 residential neighborhoods at the end of 2014. The total area of residential neighborhoods was $176.31 \mathrm{~km}^{2}$, accounting for $26.4 \%$ of the entire five-ring area $\left(667.8 \mathrm{~km}^{2}\right)$. The size of neighborhoods ranged from 0.1 to 100 hectares, with an average of 5.64 hectares. Neighborhoods with larger areas were mostly distributed outside of the 4th ring road, particularly in the newly developed southern urban sections, however the external southern sections had the lowest neighborhood density and largest mean greenspace patch size. The total area of residential greenspace was $41.07 \mathrm{~km}^{2}$, which covered $23.29 \%$ of the total urban residential area, with an average greenspace of 1.32 hectares per neighborhood. The neighborhoods density slightly decreased, but the average neighborhoods size increased with increasing distance to the city center (Tian'anmen square).

Few neighborhoods $(3.01 \%)$ had been constructed more than 35 years (before 1978), as massive demolitions and redevelopments occurred in the inner-city in the 1990s, and some Hu-tongs were considered preserved cultural relics rather than housing commodities. Together with neighborhoods of 27-35 years old (1979-1987), these older neighborhoods were mostly distributed within the 2 nd ring road (Table 4; Fig. 3). Almost half (44.25\%) of the total neighborhoods were 10-16 years old (1998-2004); 
Table 4 The quantitative distribution of Beijing urban neighborhoods

\begin{tabular}{|c|c|c|c|c|c|c|c|c|}
\hline Age & Number & Fraction (\%) & Unit price $^{\mathrm{ab}}$ & Number & Fraction (\%) & Plot ratio & Number & Fraction (\%) \\
\hline $0-9$ & 533 & 17.08 & $1-3$ & 226 & 7.24 & $0-1$ & 292 & 9.36 \\
\hline $10-16$ & 1506 & 44.25 & $3-5$ & 1574 & 50.43 & $1-2$ & 1053 & 33.74 \\
\hline $17-26$ & 699 & 26.4 & $5-7$ & 1075 & 34.44 & $2-3$ & 1036 & 33.19 \\
\hline $27-35$ & 289 & 9.26 & $7-9$ & 204 & 6.54 & $3-4$ & 464 & 14.87 \\
\hline $36-$ & 94 & 3.01 & 9- & 42 & 1.35 & $4-5$ & 157 & 5.03 \\
\hline \multicolumn{3}{|c|}{ Until December 2014} & \multicolumn{2}{|c|}{$\times 10^{4} \mathrm{CNY} / \mathrm{m}^{2}$} & & $5-$ & 119 & 3.81 \\
\hline Type & & Number & \multicolumn{2}{|c|}{ Fraction (\%) } & Location & \multicolumn{2}{|c|}{ Number } & Fraction (\%) \\
\hline VI & & 54 & \multicolumn{2}{|l|}{1.73} & INE & \multicolumn{2}{|c|}{342} & 10.96 \\
\hline LR & & 211 & \multicolumn{2}{|l|}{6.76} & INW & \multicolumn{2}{|c|}{448} & 14.35 \\
\hline MR & & 1760 & \multicolumn{2}{|l|}{56.39} & ISE & \multicolumn{2}{|c|}{224} & 7.18 \\
\hline MHR & & 223 & \multicolumn{2}{|l|}{7.15} & ISW & \multicolumn{2}{|c|}{355} & 11.37 \\
\hline SHR & & 459 & \multicolumn{2}{|l|}{14.71} & ENE & \multicolumn{2}{|c|}{437} & 14.01 \\
\hline THR & & 414 & 13.26 & & ENW & \multicolumn{2}{|c|}{597} & 19.12 \\
\hline \multirow{2}{*}{\multicolumn{5}{|c|}{ Based on average height and architectural form }} & ESE & \multicolumn{2}{|c|}{268} & 8.59 \\
\hline & & & & & ESW & \multicolumn{2}{|c|}{450} & 14.42 \\
\hline
\end{tabular}

${ }^{\text {a }}$ The average exchange rate was $6.2 \mathrm{CNY}$ per USD in December, 2014

${ }^{\mathrm{b}}$ The integers were included in the former class

$26.4 \%$ were 17-26 years old (1988-1997), and $17.08 \%$ were less than 9 years old (after 2005). While neighborhoods less than 16 years old were spread over the whole five-ring area, the neighborhoods of 17-26 years were concentrated approximately between the 2 nd -4 th ring roads, particularly in the northern urban sections (Fig. 3-Age).

Most neighborhoods $(84.87 \%)$ had a unit price of 3-7 $\times 10^{4} \mathrm{CNY} / \mathrm{m}^{2}$, and the proportions of unit price $<3 \times 10^{4} \mathrm{CNY} / \mathrm{m}^{2}$ and $>7 \times 10^{4} \mathrm{CNY} / \mathrm{m}^{2}$ were $7.24 \%$ and $8.89 \%$, respectively (Table 4 ). Approximately half $(50.34 \%)$ of the total neighborhoods were priced at $3-5 \times 10^{4} \mathrm{CNY} / \mathrm{m}^{2} ; 34.44 \%$ were priced at $5-7 \times 10^{4} \mathrm{CNY} / \mathrm{m}^{2}$. When further subdividing the price ranges, neighborhoods priced at $4-5 \times 10^{4} \mathrm{CNY} / \mathrm{m}^{2}$ occupied the highest proportion $(27.1 \%) ; 23.81 \%$ of the neighborhoods were 5-6 $\times 10^{4} \mathrm{CNY} / \mathrm{m}^{2}$, and $23.24 \%$ of neighborhoods were $3-4 \times 10^{4} \mathrm{CNY} / \mathrm{m}^{2}$. Spatially, the neighborhoods priced $<3 \times 10^{4} \mathrm{CNY} / \mathrm{m}^{2}$ were mainly distributed in the southern urban sections, especially outside of the 4th ring road, whereas neighborhoods priced $>7 \times 10^{4} \mathrm{CNY} / \mathrm{m}^{2}$ were mostly located within internal urban sections. Some neighborhoods priced 5-7 $\times 10^{4} \mathrm{CNY} / \mathrm{m}^{2}$ were also located within the 2nd ring road; however, many of them were outside of the 2 nd ring road, with outgoing radiation in the northwestern direction from 2nd ring road to the 4th ring road. Additionally, the neighborhoods priced $3-5 \times 10^{4} \mathrm{CNY} / \mathrm{m}^{2}$ were mostly located north of the southern 4th ring road, but few were located in the area within the 2 nd ring or in the area from the 2nd ring to the 5th ring in the northwestern direction (Fig. 3-Unit price).

The neighborhoods with plot ratio $<1$ and $>4$ were similarly proportioned, at $9.36 \%$ and $8.84 \%$, respectively. Moreover, the proportions of neighborhoods with plot ratio of 1-2 and 2-3 were also quite similar, ranging from $33.74 \%$ to $33.19 \%$ (Table 4 ). The neighborhoods with plot ratio $<1$ were mostly distributed within the 2nd ring road, and few were outside the 4 th ring road. Although the neighborhoods with plot ratios of 1-2 and 2-3 randomly distributed, they had different aggregated clusters. The neighborhoods with plot ratio of 1-2 were concentrated in the outermost areas of the northwestern and southern urban sections, while those with plot ratio of 2-3 were in the outermost areas of the eastern urban sections. In addition, neighborhoods with plot ratio $>4$ were mostly distributed within the 4th ring road, and 
neighborhoods with plot ratio of 3-4 extended the distribution to several further urban sections outside of the 4th ring road in the western and northeastern urban directions (Fig. 3-Plot ratio).

Regarding the neighborhood types, more than half neighborhoods were multiple-rises $(56.39 \%)$, and the proportion of high-rises was approximately half $(27.97 \%)$ of multiple-rises. The proportions of midhigh-rises $(7.15 \%)$ and low-rises $(6.76 \%)$ were similar, followed by villas (1.73\%). Most villas (39 of 54) were located outside of the 4th ring road, with aggregation within the external northwestern section, whereas the majority of low-rises (184 of 211) covered almost the entire 2nd ring area. Multiple-rises and mid-high-rises were randomly spread over the fivering area without aggregation. In addition to the 4th ring area, high-rises also aggregated in several sections outside of the 4th ring road, from the northern to eastern urban sections, with few differences between slab-types and tower-types (Fig. 3-Type).

The number of neighborhoods increased from internal to external urban sections along with the ring roads. There were fewer neighborhoods within the 3rd ring road $(43.85 \%)$ than outside the 3 rd ring road $(56.15 \%)$. The proportion of neighborhoods (17.2\%) within the 2nd ring road $\left(62.81 \mathrm{~km}^{2}\right)$ was significantly less than those within the other ring road areas, which were similar, ranging from $27 \%$ within the 2 nd-3rd ring roads $\left(95.8 \mathrm{~km}^{2}\right)$ to $27.7 \%$ in the $3 \mathrm{rd}-4$ th ring roads $\left(143.7 \mathrm{~km}^{2}\right)$ to $28.1 \%$ in the 4 th -5 th ring roads $\left(365.53 \mathrm{~km}^{2}\right)$. However, different scenarios were observed for the neighborhood density: the area between the 2 nd and $3 \mathrm{rd}$ ring roads had the highest density $\left(8.8 / \mathrm{km}^{2}\right)$, followed by $8.55 / \mathrm{km}^{2}$ within the 2nd ring road, $6.01 / \mathrm{km}^{2}$ within the $3 \mathrm{rd}-4$ th ring roads, and $2.4 / \mathrm{km}^{2}$ within the 4 th- -5 th ring roads. With respect to the eight sections in Fig. 3-Location, there were more neighborhoods in the northern urban sections $(58.44 \%)$ than in the southern urban sections $(41.56 \%)$. The northwestern urban sections $(33.47 \%$, INW and ENW) had the most neighborhoods, followed by the southwestern urban sections $(25.79 \%$, ISW and ESW) and northeastern urban sections (24.97\%, INE and ENE), while the southeastern urban sections (15.77\%, ISE and ESE) had the least. However, for neighborhood density, INE $\left(9.53 / \mathrm{km}^{2}\right)$ and INW $\left(9.01 / \mathrm{km}^{2}\right)$ were the only two sections with neighborhood densities higher than $9 / \mathrm{km}^{2}$, followed by ISW $\left(8.2 / \mathrm{km}^{2}\right)$ and ISE $\left(7.62 / \mathrm{km}^{2}\right)$. The neighborhood densities in ENE $\left(4.42 / \mathrm{km}^{2}\right)$ and ENW $\left(4.53 / \mathrm{km}^{2}\right)$ were approximately half those in INW, and $\operatorname{ESW}\left(2.75 / \mathrm{km}^{2}\right)$, and the density in $\operatorname{ESE}\left(2.33 / \mathrm{km}^{2}\right)$ was the lowest (Fig. 3-Location).

Landscape characteristics of Beijing residential greenspace

The residential greenspace landscapes greatly varied in terms of neighborhood characteristics. The average green coverage of all neighborhoods was $22.82 \%$. The neighborhoods of 17-26 years old were most vegetated $(23.56 \%)$, while those of $10-16$ years old were the least $(21.19 \%)$. For neighborhoods more than 16 years old, the green coverage significantly decreased with increasing age. In addition, for all neighborhoods, increased age led to a substantial increase in the fractal dimension, edge density and patch density; however the mean patch size and patch size coefficient of variance substantially decreased. Compared to other age classes, the neighborhoods of 10-16 years old behaved differently and had a less predictable edge density, vegetation coverage and patch size coefficient of variance. The neighborhoods built before 1998 were more vegetated than those built after 1998. Moreover, the older neighborhoods were more likely to have a complex shape and more fragmented greenspace (Fig. 5-Neighborhood age; Online Appendix Table A).

Most metrics were fluctuated and unpredictable in response to unit price. While the vegetation coverage was approximately shaped as a "w" curve, the fractal dimension showed a "fall-rise-fall" change. The edge density and patch size coefficient of variance showed a "fall-significant rise" change with increasing unit price, whereas the patch density had a "rise-slight fall" trend, with a peak value at $7-9 \times 10^{4} \mathrm{CNY} / \mathrm{m}^{2}$. The greenspace landscapes of neighborhoods with higher unit prices tended to be more vegetated and more fragmented and had higher variations in patch size (Fig. 5-Unit price; Online Appendix Table A).

The landscape metrics response to the plot ratio were more consistent than those to the unit price. Although all metrics generally demonstrated a decreased change with increasing plot ratio, the magnitude of the decrease depended on the metrics. The changes in vegetation coverage could be merged into 3 groups (plot ratio $<2 ; 2-4$; and $>4$ ). The vegetation coverage decreased with increasing plot 
ratio groups, but within each group, the coverage changed little. The edge density and patch size coefficient of variance were also regrouped into three groups but with quite different ranges. The values of the neighborhoods of plot ratio $<1$ were significantly greater than those of plot ratio $1-4$, which were significantly greater than those of plot ratio $>4$. The fractal dimension showed similar trend as the edge density, except the increased value at plot ratio of 4-5. The fractal dimension, patch density and mean patch size showed "fall-rise" changes, with plot ratio of 4-5 as the turning point. The neighborhoods with higher plot ratios usually produced greenspace landscapes that were less vegetated, simpler in shape and less fragmented (Fig. 5-Plot ratio; Online Appendix Table A).

Villas were unique among the neighborhood types based on the performances of the landscape metrics. The vegetation coverage, edge density, and patch size coefficient of villas were significantly greater than those of the other neighborhood types; the same was true for the other metrics for at least three of the neighborhood types. Without considering villas, four indices, edge density, fractal dimension, patch density and patch size coefficient, generally presented decreasing trends with increasing building height, while vegetation coverage and mean patch size showed "rise-fall" changes. In addition, for most metrics, tower-type high-rises showed inconsistent changes compared to slab-type high-rises. Except for villas, the neighborhoods with greater heights generally resulted in simply shaped and less fragmented greenspace landscapes (Fig. 5-Neighborhood type; Online Appendix Table A).

The neighborhoods outside of the 3rd ring road had significantly higher vegetation coverage, edge density, mean patch size and patch size coefficients than those within the 3rd ring road (Fig. 4). Regarding these four metrics, the values of the neighborhoods located in the eastern urban sections were higher than those in the corresponding western urban sections regardless of being in the internal or external urban sections. However, the fractal dimension and patch density experienced exactly opposite trends. The fractal dimensions of the neighborhoods in the external and eastern urban sections were significantly lower than those in the internal and corresponding western urban sections. Specifically, the southwestern urban sections were least vegetated, whereas the southeastern urban sections were most vegetated in both the internal and external urban areas (Fig. 4). The patch densities in the internal northern sections were significantly greater than those in the other sections; however, the edge density, mean patch size and patch size coefficient were lowest in the northern sections (Fig. 5Neighborhood location; Online Appendix Table A).

Effects of neighborhood characteristics on residential greenspace landscapes

The magnitudes and directions of correlations depended on the landscape metrics and neighborhood characteristics observed from all 3121 neighborhoods. The plot ratio was significantly correlated with all six landscape metrics $(r=-0.68$ to $-0.15, p \leq 0.05)$, followed by five metrics of the distance to the city center $(\mathrm{r}=-0.52-0.43, \mathrm{p} \leq 0.05)$, four metrics of neighborhood age $(\mathrm{r}=-0.46$ to $0.69, \mathrm{p} \leq 0.01)$ and average height $(\mathrm{r}=-0.64$ to $-0.21, \mathrm{p} \leq 0.01)$. The least correlated characteristic was unit price (two metrics; $\mathrm{r}=0.34-0.44, \mathrm{p} \leq 0.01$ ), which was only significantly correlated with vegetation coverage and patch density (Table 5). With respect to the landscape metrics, patch density was the only metric significantly correlated with all neighborhood characteristics. Additionally, the mean patch size and patch size coefficient of variation were correlated with the four neighborhood characteristics, and vegetation coverage, edge density and fractal dimension were correlated with three characteristics. Specifically, vegetation coverage was positively correlated with unit price $(\mathrm{r}=0.34, \mathrm{p} \leq 0.01)$ and distance to the city center $(r=0.33, p \leq 0.01)$ but negatively correlated with the plot ratio $(\mathrm{r}=-0.26, \mathrm{p} \leq 0.01)$. Most metrics were significantly correlated with these characteristics, except for the edge density was nonsignificantly ( $p \geq 0.05$ ) correlated with the neighborhood age, unit price and distance to the city center; similar results were found for the fractal dimension to unit price $(p \geq 0.05)$, the mean patch size to the unit price and average height ( $p \geq 0.05)$, and the patch size coefficient of variation to the unit price $(p \geq 0.05)$ (Table 5).

Based on the results of the regression analyses using all 3121 neighborhoods, each of the five neighborhood characteristic was important for predicting at least two landscape metrics (Table 6). Plot ratio was the most crucial predictor for landscape 


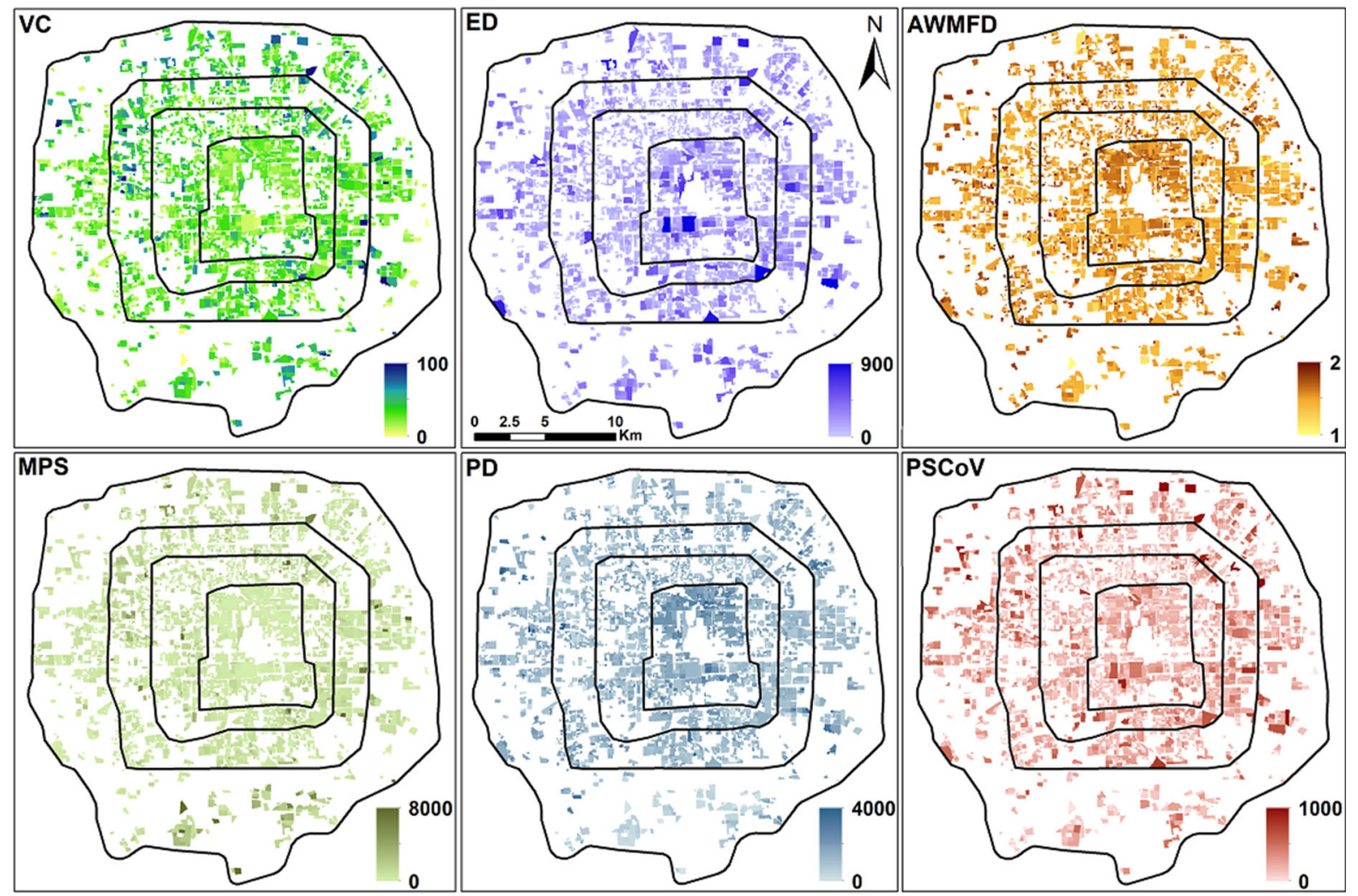

Fig. 4 The spatial variations of greenspace landscape metrics of Beijing urban neighborhoods

configurations, such as, edge density, fractal dimension and patch size coefficient of variation. A neighborhood with one unit higher plot ratio decreased the edge density by 5.66 , the fractal dimension by 0.003 , and the patch size coefficient of variation by 7.03 . Meanwhile, distance to the city center (Tian'anmen square) was the most crucial predictor for vegetation coverage and mean patch size, which increased $0.16 \%$ and $10.17 \mathrm{~m}^{2}$ when a neighborhood was one additional kilometer distant to the city center. Additionally, neighborhood age was the most crucial factor for predicting patch density (landscape fragmentation), and neighborhoods that were one year older increased the patch density by 8.69 . Unit price was also important to the vegetation cover (following distance to the city center) and patch density (following neighborhood age), while average height was relatively important to the edge density (following plot ratio). All regression models were significant ( $p$ $\leq 0.01$ ), and the model for patch density had the best model fitness, as suggested by the adjusted $\mathrm{R}^{2}$ value
(0.83), while the fractal dimension had the lowest (0.43, Table 6).

\section{Discussion}

Spatial and quantitative variations of Beijing urban neighborhoods

The distributional disparities of Beijing urban neighborhoods result from the combining effects of urbanization mode (Yu and Zhou 2017) and urban housing policies (Leaf 1995; Wang 2001). Serving as the capital city for six ancient dynasties since the eleventh century, Beijing has inherited both original urban patterns and numerous relics. These historical roots played a crucial role on the development of urban structure, for instance, keeping the historical old town as it is and extending the urban boundary to suburban. The expansion of Beijing urban area from the secondring area to the five-ring area, and the population of Beijing city increased from 10.9 million of 1990 to 

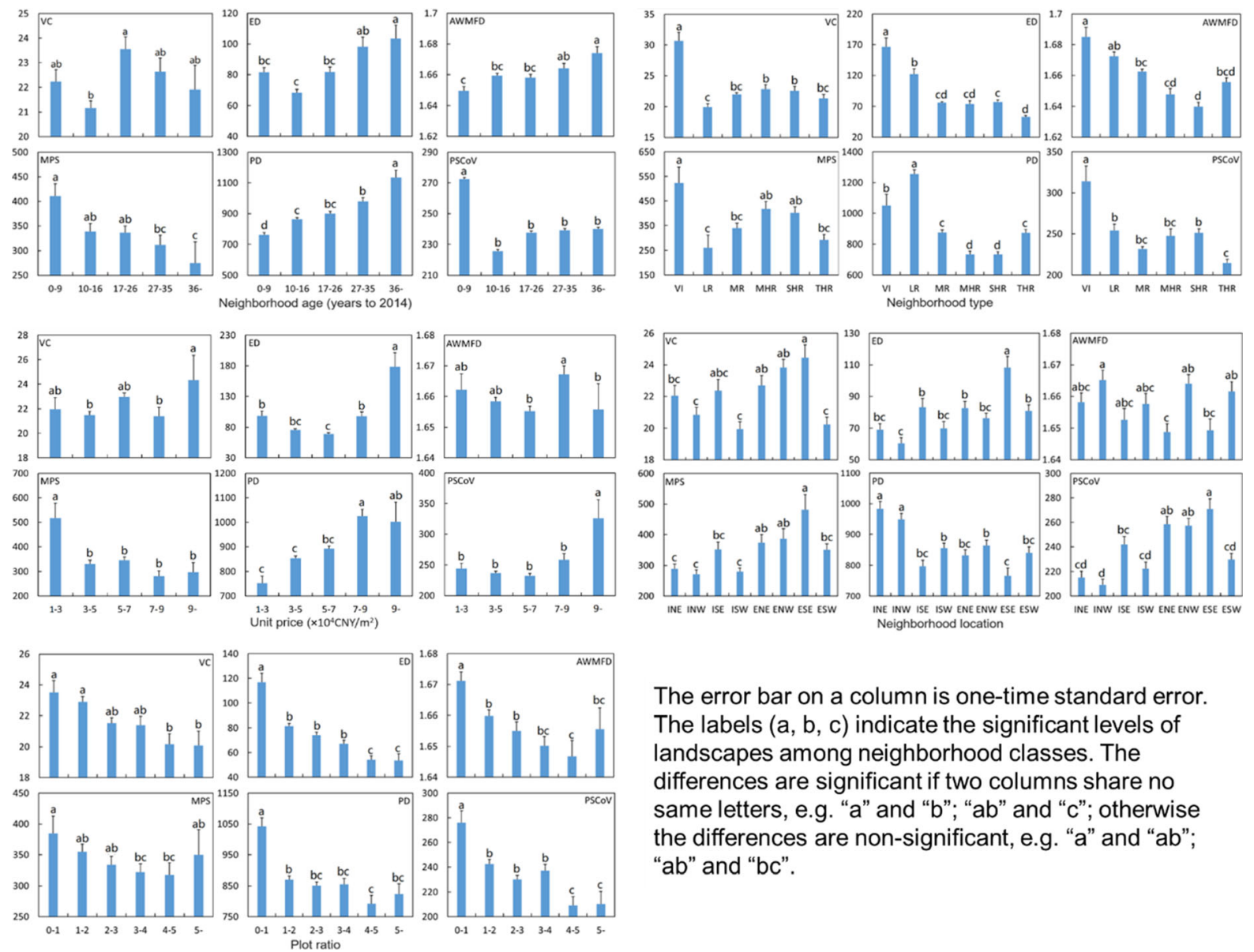

The error bar on a column is one-time standard error.

The labels $(a, b, c)$ indicate the significant levels of landscapes among neighborhood classes. The differences are significant if two columns share no same letters, e.g. "a" and "b"; "ab" and "c"; otherwise the differences are non-significant, e.g. "a" and "ab"; "ab" and "bc".

Fig. 5 The residential greenspace landscapes in terms of neighborhood characteristics. The abbreviations of titles and $\mathrm{X}$ axises are respectively indicated in Table 3 and Table 4

Table 5 The correlation analysis of residential greenspace landscape metrics and characteristics of 3121 urban neighborhoods

\begin{tabular}{lccccc}
\hline & Age & Unit Price & Plot ratio & Average height & Distance to city center \\
\hline VC & -0.12 & $0.34^{* *}$ & $-0.26^{* *}$ & -0.1 & $0.33^{* *}$ \\
ED & 0.16 & 0.08 & $-0.68^{* *}$ & $-0.64^{* *}$ & 0.09 \\
AWMFD & $0.54^{* *}$ & -0.07 & $-0.44^{* *}$ & $-0.46^{* *}$ & $-0.24^{*}$ \\
PD & $0.69^{* *}$ & $0.44^{* *}$ & $-0.51^{* *}$ & $-0.39^{* *}$ & $-0.52^{* *}$ \\
MPS & $-0.46^{* *}$ & 0.05 & $-0.15^{*}$ & 0.12 & $0.43^{* *}$ \\
PSCoV & $-0.27^{* *}$ & 0.06 & $-0.31^{* *}$ & $-0.21^{* *}$ & $0.32^{* *}$ \\
\hline
\end{tabular}

*Significant at the 0.05 level

**Significant at the 0.01 level (2-tailed)

21.7 million of 2015 (Beijing Municipal Bureau of Statistics 2016). Those dramatic expansion on urban buildings and population density resulted in the generally decreased neighborhood age and housing density from urban core to fringe area. Although the 2nd-3rd and 3rd-4th ring road had a similar number of neighborhoods (843 and 864), the neighborhood densities were greatly different $\left(8.8 / \mathrm{km}^{2}\right.$ and $6.01 /$ 
Table 6 Multiple regression analysis of residential greenspace landscape metrics and characteristics of 3121 urban neighborhoods

\begin{tabular}{|c|c|c|c|c|c|c|c|}
\hline & \multicolumn{5}{|c|}{ Regression Coefficients } & \multirow[t]{2}{*}{ Adjusted $\mathrm{R}^{2}$} & \multirow[t]{2}{*}{ AIC value } \\
\hline & Age & Unit price & Plot ratio & Average height & Distance to city center & & \\
\hline \multirow[t]{2}{*}{$\mathrm{VC}$} & -0.01 & $0.02 * *$ & $-0.23 * *$ & -0.01 & $0.16 * *$ & \multirow[t]{2}{*}{$0.61 * *$} & \multirow[t]{2}{*}{4547.63} \\
\hline & -0.31 & 0.93 & -0.45 & -0.26 & 1.33 & & \\
\hline \multirow[t]{2}{*}{ ED } & $0.58^{*}$ & $9.22 * *$ & $-5.66 * *$ & $-0.63 * *$ & $1.26 * *$ & \multirow[t]{2}{*}{$0.72 * *$} & \multirow[t]{2}{*}{7329.06} \\
\hline & 0.81 & 0.4 & -1.22 & -1.05 & 0.75 & & \\
\hline \multirow[t]{2}{*}{ AWMFD } & $-1.35 \mathrm{E}-3 * *$ & $-1.68 \mathrm{E}-4 * *$ & $-3.24 \mathrm{E}-3 * *$ & $-5.17 \mathrm{E}-3 * *$ & $4.95 \mathrm{E}-4 * *$ & \multirow[t]{2}{*}{$0.43 * *$} & \multirow[t]{2}{*}{-9521.24} \\
\hline & -0.78 & -0.33 & -0.95 & -0.53 & 0.27 & & \\
\hline \multirow[t]{2}{*}{ MPS } & $-2.13 * *$ & 19.49 & 4.01 & 2.05 & $10.17 * *$ & \multirow[t]{2}{*}{$0.54 * *$} & \multirow[t]{2}{*}{$17,481.12$} \\
\hline & -0.58 & 0.07 & -0.09 & 0.14 & 0.96 & & \\
\hline \multirow[t]{2}{*}{ PD } & $8.69 * *$ & $14.57 * *$ & $-10.51 * *$ & $-1.87 * *$ & -12.23 & \multirow[t]{2}{*}{$0.83 * *$} & \multirow[t]{2}{*}{$24,365.81$} \\
\hline & 1.53 & 0.88 & -0.57 & -0.31 & -0.19 & & \\
\hline \multirow[t]{2}{*}{ PSCoV } & $-1.06 * *$ & $6.24 * *$ & $-7.03 * *$ & $-0.22 * *$ & $2.38 * *$ & \multirow[t]{2}{*}{$0.75^{* *}$} & \multirow[t]{2}{*}{$10,354.97$} \\
\hline & -0.42 & 0.28 & -0.89 & -0.49 & 0.67 & & \\
\hline
\end{tabular}

The italic rows are standardized coefficients. F-statistic is used to test the model as a whole (Adjusted $\mathrm{R}^{2}$ ), and $\mathrm{t}$-statistic for individual coefficients (Regression Coefficients)

*Significant at the 0.05 level (2-tailed)

**Significant at the 0.01 level (2-tailed)

$\mathrm{km}^{2}$ ) because the area of the $3 \mathrm{nd}-4 \mathrm{rd}$ ring road area $\left(143.7 \mathrm{~km}^{2}\right) 1.5$ times larger that of the $2 \mathrm{rd}-3$ th ring road area $\left(95.8 \mathrm{~km}^{2}\right)$. The lower neighborhood densities offered more potential for lands to be green, as there was increasing demands from residents for more visible greenspace. During the urban expansion, the northern urban areas, especially the northwestern sections, gained more popularity because of aesthetically natural elements ("Feng-Shui"), including mountains, rivers and forests (Zhao et al. 2011). Moreover, Liu et al. (2017) revealed the spatial distribution of the fast non-agriculturization began to shift from the northern urban area to the southern urban area after 2005. This phenomenon was supported by our results that neighborhoods in the northern urban sections (INW, ENW, INE, and ENE) outnumbered corresponding sections in the southern urban, and northern urban sections had more aged neighborhoods (Fig. 3-Age). Furthermore, the neighborhoods in the northwestern sections (INW and ENW) had higher average unit prices, while the lagging developed southern urban sections (ESW and ESE) had significantly lower neighborhood unit prices and lower neighborhoods densities (Table 4; Fig. 3).

Regarding the urban housing development, several radical reforms affected the urban housing construction. After the "reform and opening up" policy in 1978, numerous "internal immigrants" crowded into Beijing, which further aggravated the living conditions of local residents (Beijing Municipal Bureau of Statistics 2016). To accommodate the increasing population, housing developers were allowed to build on state and collective lands through auction and negotiation for the first time in the late 1980s (Zheng and Kahn 2008). Shortly thereafter in 1990s, the "demolition and redevelopment" campaigns allocated substantial proportions from innercity residents to suburban areas to retain the original housing patterns of "old town" and to improve the living conditions of local residents (Leaf 1995). These relocations led to more aged neighborhoods of internal urban. Meanwhile, urban workers needed to purchase houses from commercial developers since the welfareoriented housing policy was displaced by the commercial housing market. These radical housing reforms resulted in numerous houses being continually added into the housing stock. Until 2015, $90.28 \%$ of urban houses were constructed after 1985, and 71.63\% of them were constructed after 1998. Additionally, the newly built houses has shifted from multiple-rise in 1980 s to high-rise neighborhoods in 2000s to accommodate more populations (Table 3; Fig. 3). 
Landscape variations of urban residential greenspace

\section{Greenspace coverage}

While Zheng et al. (2017) demonstrated that Beijing urban neighborhoods that were built recently tended to have less vegetation coverage, our results showed that middle-aged neighborhoods of 17-26 years old were the most vegetated, and neighborhoods of 10-16 years old were least vegetated. From the 1950s to the early 1980s, houses were mainly built by state and collective units to address housing shortages; however, greenspace was of little concern in regard to housing quality. By the late 1980 s, the housing policy encouraged improving housing quality to meet the demands of the higher expectations from residents, and increasing the green density was a straightforward way to accomplish this goal. In general, enough time had lapsed for the trees to have canopy growth in the aged neighborhoods that were more than 20 years old. However, the neighborhoods older than 26 years (built before 1988) were less vegetated than the neighborhoods of 17-26 years (built between 1988 and 1997). The differences mainly because more aged neighborhoods were low-rises located within densely populated "old town", meanwhile the "demolition and redevelopment" campaigns implemented in early 1990s that relocated inner-city residents to suburban areas allowing more space for residential greening. This was also the main reason why external urban sections were more vegetated than internal urban sections. The neighborhoods of 10-16 years (built between 1998 and 2004) were least vegetated. Housing developers started to care about greenspace qualities that were regulated by the Urban Housing and Real Estate Management Act issued in 1995 (Wang 2001; Tan et al. 2005); however, in a substantial number of neighborhoods, the greenspace had not been well managed or maintained, leading to severe degradation after only several years of construction. In contrast, at least a $30 \%$ greening rate for newly constructed neighborhoods became a mandatory provision of the Beijing housing market in 2010 (Beijing Municipal People's Congress 2009), which result in the increased greenspace coverage and connectivity in neighborhoods built after 2005 (Fig. 5). However, the newly built high-rises would shade more surrounding greenspace, which was difficult to be recognized from satellite images (Yan et al. 2018). In addition, compared with $2.5 \mathrm{~m}$ spatial resolution satellite images used by Zheng et al. (2017), our $0.5 \mathrm{~m}$ spatial resolution images were capable of recognizing more scattered and shaded greenness (Qian et al. 2015b; Li et al. 2013). The difference observations between Zheng et al. (2017) and us partially resulted from those recognition issues.

In contrast to the middle-aged neighborhoods (17-26 years) were most vegetated, the plot ratio showed consistently negative relationships with vegetation coverage. A neighborhood of higher plot ratio tends to include more newer and taller buildings. In addition to newly built houses usually were less vegetated as suggested by our results, more greenspace would be shaded by high-rises contrasting to low-rises also contribute the consistent decreases of green coverage responding to increasing plot ratio. Moreover, a neighborhood with higher plot ratio usually has a smaller ground floor area but accommodate a greater population density. For these neighborhoods, there were few lands left for greening except for necessary living infrastructure, even though the greenness was more likely to be transferred to other usages, e.g., internal roads, parking lots. With respect to housing location, for both internal and external urbans, the neighborhoods in south-western sections always had the lowest greenspace proportion. The southern urban sections were much lagging developed. One of the main objectives of Beijing city master plan (2004-2020) was control the population scale and urban expansion of northern urban sections and accelerate the development of southern and eastern urban sections. Therefore the neighborhoods in south-western sections are mostly newly built houses less than 16 years old, which were less vegetated than the other neighborhoods (Fig. 3). In addition, the "w" shaped response by vegetation coverage to unit price is notable (Fig. 5). All of the neighborhoods with lower plot ratios, e.g., Hu-tongs and the majority of low-rises in our classifications, were relatively less vegetated; however, villas were significantly more vegetated, which is consistent with worldwide studies (Kirkpatrick et al. 2012; Clarke et al. 2013).

\section{Greenspace configurations}

In addition to the inherent complexities of configurations, the dramatic changes over the past several 
decades has aggravated the uncertainties of configuration dynamics (Fig. 4). The plot ratio and neighborhood age had fewer variations in relation to the configuration metrics as suggested by Fig. 5. More aged neighborhoods tended to have higher green patch densities but smaller mean patch sizes because of the isolated tree canopies, the degradation of greenness, and also the scattered dispersion of wild growth. However, the large central gardens and insufficiently scattered trees surrounding the buildings in newer neighborhoods increased the variations in patch size and edge complexities (Fig. 5). Therefore, given the same amount of greenspace, the more aged neighborhoods were more likely to have smaller mean patch sizes and more complex shape characteristics but fewer size variations among greenspace patches.

Plot ratio and neighborhood type were all related to building height but emphasized different attributes. The plot ratio is based on building height/density and floor area, while the neighborhood type incorporate building height and building architecture. For instance, slab-type and tower-type high-rises had similar plot ratios but distinct building architectural styles, as did villas and low-rises. Building architectural style affects landscape configurations by determining the horizontal and vertical dimensions of buildings and then the availability of potential greening lands. Therefore, the mean patch sizes and patch densities of villas and low-rises were markedly different, and the configurations of tower-type highrises were more similar to multiple-rises than slabtype high-rises as shown in Fig. 5-Neighborhood type. These exceptions suggest the requirements of intensively evaluating systems. In addition, the changes in the fractal dimension in response to plot ratio and neighborhood type suggested that a taller building height or compact building density simplified the shape characteristics of green patches because fewer greening options were limited by building pattern arrangements and less land availabilities.

\section{Predictors of greenspace landscapes for Beijing urban neighborhoods}

Among the neighborhood characteristics, distance to city center and plot ratio were the most crucial predictors to the greenspace coverage and configurations of Beijing urban neighborhoods as suggested by our results. Similar results also suggested by existing evidence of Grove et al. (2006) that three social theories (social stratification, lifestyle behavior, and population density) could mainly explain the landscape variations in private gardens. For example, the plot ratio in our analysis considerably represents the population density, and the distance to city center were more related to lifestyle behavior, Our results that the green density were positively related to the distance to the city center was consistent with previous studies that housing parcels that are more distant from the urban core have larger green yards (Haase et al. 2019), and low density neighborhoods have the highest vegetation cover (Clarke et al. 2013). However, the house price of Beijing neighborhoods, which may correspond to social stratification and landscape prestige (Grove et al. 2006), was not significant to residential landscapes in our case. This inconsistences mainly resulted from urban housing structure and greening management strategies. First, the "edgeexpansion" mode (Yu and Zhou 2017) of urban development resulted in the relative high unit price of $\mathrm{Hu}$-tongs, which are least vegetated among the neighborhood types. Second, the higher population density in Beijing urban area reduces the average greenspace per capita. Third, the greenspace of most Beijing urban neighborhoods was designed and managed by property companies. Therefore, unlike that in American and European cities (Nasar 1989), less possibilities were provided to residents to highlight the prestige of their neighborhoods through greening preferences. Overall, unit price should be carefully applied to predictions because the relation of unit price and greenspace landscapes were highly affected by higher greenspace density of villas and the higher patch density of Hu-tongs (Fig. 5-Unit price).

Plot ratio was the most crucial predictor for three of the five selected configuration metrics: edge density, fractal dimension and patch size coefficients of variation. Given a certain population, a neighborhood with a higher plot ratio generally covers a smaller area of ground plot for the case of Beijing urban area. Thus, higher population density demands more lands of living infrastructure and squeezes the potential greenspace at the same time. In addition, to avoid the limited view of skyline, higher plot ratio neighborhoods need more space between two high buildings. Therefore, the most common greening pattern for such neighborhoods is one central garden combining scattered but connected greenspace surrounding the buildings for tower-type 
high rises, or several large greenspace between slabtype high rises, which all differed from the more patch numbers but smaller green patch size in neighborhoods of lower rises. Jiao et al. (2017) suggested for a fixed amount of greenspace, the total edges are positively related to patch numbers, and more edges possibly result in more complex shape characteristics. In sum, higher plot ratio neighborhoods generally are to be fewer patch density, more regular shape characteristics, and similar patch size among green patches.

Neighborhood age, to some extent, was positively related to distance to the city center considering the urban expansion strategy. However, different from distance to the city center that was crucial to vegetation coverage, neighborhood age was more predictive for patch density. More aged neighborhoods had more spacious tree canopies because they had been planted longer, but poor greening management declined the grasslands to vacant lands or other land uses, which increased the patch densities but decreased the green density. Regarding the urban sections, our results also observed both similarities and differences contrasting to existing findings. On one hand, we verified that the significant differences of greenspace landscapes in different directions of urban zones (Huang et al. 2017). On the other hand, we suggested the residential greenspace in more distant neighborhoods from the urban center generally had more greenspace, less patches but larger patch size (Fig. 5-Neighborhood location), while Qian et al. (2015a) has suggested more greenspace cover, more patch density and smaller mean patch size in the fringe area (Zhang et al. 2015).

\section{Conclusions}

Residential neighborhoods are the main potential areas of increasing urban green density as it covers considerable urban lands, and existing studies have proposed that residential greenspace evolves over time in terms of social and neighborhood characteristics. Therefore, additional evidence regarding how residential greenspace structure changes across urban neighborhoods is fundamentally needed. This study, for the first time, quantified landscape variations in urban beighborhoods and examined the relations of neighborhood characteristics and greenspace landscapes in Beijing residential areas by combining use of delineated neighborhood boundaries and urban greenmap derived from Pleiades-1A.
In 2014, the Beijing urban area had 3121 residential neighborhoods, and $23.29 \%$ of the urban residential area was covered by greenspace $\left(41.07 \mathrm{~km}^{2}\right)$. The increased distance to the city center decreased the neighborhood age and greenspace density, while increased the plot ratio and average building height of a neighborhood. Regarding landscape predictors, the influences of plot ratio were more concentrated on the configurations: edge density, shape characteristics and patch size coefficient of variation. A plot ratio that was one unit higher resulted in a 5.66 lower edge density, a 7.03 lower patch size coefficient of variation, and a 0.003 lower fractal dimension. Meanwhile, distance to the city center was more crucial for green density and mean patch size. One additional kilometer distant to the city center increased the vegetation coverage by $0.16 \%$ and the mean patch size by $10.17 \mathrm{~m}^{2}$. Moreover, neighborhood age was also important to landscape fragmentation. A neighborhood of one year older increased the patch density by 8.69.

Our examination suggested that urban housing structure is crucial to urban residential greenspace landscapes of the urbanizing Beijing. In the future, more following case studies exemplifying additional socioeconomic factors (e.g., household structure, neighborhood stratifications, life behaviors) and more further greenspace types (e.g., trees, grass, conifer, deciduous) would be a critical addition in resolving Beijing's social-urban landscapes. Finally, through integrating landscape ecology with urban design and residential structure, a versatile framework of socialecological ecosystem optimizing urban human wellbeing and urban sustainability should be proposed.

Acknowledgements This work was supported by the National Natural Science Foundation of China (Grant Number: 41422104), the Key Research Program of Frontier Sciences, Chinese Academy of Sciences (Grant Number: QYZDB-SSWDQC034), and National Key Research and Development Program (Grant Number: 2016YFC0503004). We also appreciate the two anonymous reviewers very much for their valuable and inspiring comments.

\section{References}

Akaike H (1974) A new look at the statistical model identification. IEEE Trans Autom Contr 19:716-723

Beijing Municipal People's Congress (2009) Regulations of Beijing Municipality on Greening. Article 20 
Beijing Municipal Bureau of Statistics (2016) Beijing Statistical Yearbook. China Statistics Press

Beijing Municipal Bureau of Statistics (2006) Beijing Statistical Yearbook. China Statistics Press

Benjamini Y, Hochberg Y (1995) Controlling the false discovery rate: a practical and powerful approach to multiple testing. J R Stat Soc B 57(1):289-300

Benson BJ, MacKenzie MD (1995) Effects of sensor spatial resolution on landscape structure parameters. Landsc Ecol 10:113-120

Benz UC, Hofmann P, Willhauck G, Lingenfelder I, Heynen M (2004) Multiresolution, object-oriented fuzzy analysis of remote sensing data for GIS-ready information. ISPRS J Photogramm Remote Sens 58:239-258

Blaschke T (2010) Object based image analysis for remote sensing. ISPRS J Photogramm Remote Sens 65:2-16

Chen G, Hay GJ, Carvalho LMT, Wulder MA (2012) Objectbased change detection. Int J Remote Sens 33:4434-4457

Clarke LW, Jenerette GD, Davila A (2013) The luxury of vegetation and the legacy of tree biodiversity in Los Angeles, CA. Landsc Urban Plan 116:48-59

Cook EM, Hall SJ, Larson KL (2012) Residential landscapes as social-ecological systems: a synthesis of multi-scalar interactions between people and their home environment. Urban Ecosyst 15:19-52

Dahlkvist E, Hartig T, Nilsson A, Högberg H, Skovdahl K, Engström M (2016) Garden greenery and the health of older people in residential care facilities: a multi-level cross sectional study. J Adv Nurs 72:2065-2076

Fan C, Johnston M, Darling L, Scott L, Liao HF (2019) Land use and socio-economic determinants of urban forest structure and diversity. Landsc Urban Plan 181:10-21

Fernandez LE, Brown DG, Marans RW, Nassauer JI (2005) Characterizing location preferences in an exurban population: Implications for agent-based modeling. Environ Plan B Plan Des 32:799-820

Gascon M, Triguero-Masb M, Martínez D, Dadvand P, RojasRueda D, Plasència A, Nieuwenhuijsen MJ (2016) Residential green spaces and mortality: a systematic review. Environ Int 86:60-67

Gill SE, Handley JF, Ennos AR, Pauleit S, Theuray N, Lindley SJ (2008) Characterising the urban environment of UK cities and towns: a template for landscape planning. Landsc Urban Plan 87:210-222

Grove JM, Troy AR, O’Neil-Dunne JPM, Burch WR Jr, Cadenasso ML, Pickett STA (2006) Characterization of households and its implications for the vegetation of urban ecosystems. Ecosystems 9:578-597

Gupta K, Kumar P, Pathan SK, Sharma KP (2012) Urban neighborhood green index-A measure of green spaces in urban areas. Landsc Urban Plan 105:325-335

Haase D, Jänicke C, Wellmann T (2019) Front and back yard green analysis with subpixel vegetation fractions from earth observation data in a city. Landsc Urban Plan 182:44-54

He C, Wei A, Shi P et al (2011) Detecting land-use/land-cover change in rural-urban fringe areas using extended changevector analysis. Int J Appl Earth Obs Geoinf 13:572-585

Hope D, Gries C, Zhu WX, Fagan WF, Redman CL, Grimm NB, Nelson AL, Martin C, Kinzig A (2003) Socioeconomics drive urban plant diversity. Proc Natl Acad Sci USA 100(15):8788-8792
Huang HB, Chen YL, Clinton N, Wang J, Wang XY, Liu CX, Gong P, Yang J, Bai YQ, Zheng YM, Zhu ZL (2017) Mapping major land cover dynamics in Beijing using all Landsat images in Google Earth Engine. Remote Sens Environ 202:166-176

Huo TF, Cai WG, Ren H, Feng W, Zhu ML, Lang NN, Gao J X (2019) China's building stock estimation and energy intensity analysis. J Clean Produc 207:801-813

Jenerette GD, Harlan SL, Buyantuev A, Stefanov WL, DecletBarreto J, Ruddell BL, Myint SW, Kaplan S, Li XX (2016) Micro-scale urban surface temperatures are related to landcover features and residential heat related health impacts in Phoenix, AZ, USA. Landsc Ecol 31:745-760

Jiao M, Zhou WQ, Zheng Z, Wang J, Qian YG (2017) Patch size of trees affects its cooling effectiveness: a perspective from shading and transpiration processes. Agric For Meteorol 247:293-299

Jim CY, Chen WY (2010) External effects of neighborhood parks and landscape elements on high-rise residential value. Land Use Policy 27(2):662-670

Jim CY, Zhang H (2015) Effect of habitat traits on tree structure and growth in private gardens. Landsc Ecol 30(7):1207-1223

Kabisch N, Haase D (2014) Green justice or just green? Provision of urban green spaces in Berlin, Germany. Landsc Urban Plan 122:129-139

Kirkpatrick JB, Davison A, Daniels GD (2012) Resident attitudes towards trees influence the planting and removal of different types of trees in eastern Australian cities. Landsc Urban Plan 107(2):147-158

Kong FH, Nakagoski N (2006) Spatial-temporal gradient analysis of urban green spaces in Jinan, China. Landsc Urban Plan 78(3): 147-164

Kong FH, Yin HW, James P, Hutyra LR, He HS (2014) Effects of spatial pattern of greenspace on urban cooling in a large metropolitan area of eastern China. Landsc Urban Plan 128:35-47

Kuo FE, Sullivan WC (2001) Environment and crime in the inner city-does vegetation reduce crime? Environ Behav 33(3):343-367

Larson KL, Hoffman J, Ripplinger J (2017) Legacy effects and landscape choices in a desert city. Landsc Urban Plan 165:22-29

Leaf M (1995) Inner city redevelopment in China: implications for the city of Beijing. Cities 12:149-162

Li H, Wu J (2004) Use and misuse of landscape metrics. Landsc Ecol 19:389-399

Li XJ, Zhang CR, Li WD, Kuzovkina YA, Weiner D (2015) Who lives in greener neighborhoods? The distribution of street greenery and its association with residents' socioeconomic conditions in Hartford, Connecticut, USA. Urban For Urban Green 14:751-759

Li XM, Zhou WQ, Ouyang ZY (2013) Relationship between land surface temperature and spatial pattern of greenspace: what are the effects of spatial resolution? Landsc Urban Plan 114:1-8

Lin B, Meyers J, Barnett G (2015) Understanding the potential loss and inequities of green space distribution with urban densification. Urban For Urban Green 14(4):952-958

Liu Y, Yang Y, Li Y, Li J (2017) Conversion from rural settlements and arable land under rapid urbanization in Beijing during 1985-2010. J Rural Stud 51:141-150

Locke DH, Avolio M, Trammel T, Roy Chowdhury R, Grove JM, Rogan J, Groffman PM (2018) A multi-city 
comparison of front and backyard differences in plant species diversity and nitrogen cycling in residential landscapes. Landsc Urban Plan 178:102-111

Loram A, Tratalos J, Warren PH, Gaston KJ (2007) Urban domestic gardens $(\mathrm{X})$ : the extent \& structure of the resource in five major cities. Landsc Ecol 22(4):601-615

National Bureau of Statistics of China (2018) China Statistical Yearbook. China Statistics Press

Nasar JL (1989) Symbolic meanings of house styles. Environ Behav 21(3):235-257

Nassauer JL, Wang Z, Dayrell E (2009) What will the neighbors think? Cultural norms and ecological design. Landsc Urban Plan 92(3-4):282-292

Ossola A, Locke D, Lin B, Minor E (2019) Greening in style: urban form, architecture and the structure of front and backyard vegetation. Landsc Urban Plan 185:141-157

Pickett STA, Cadenasso ML, Grove JM, Boone CG, Groffman PM, Irwin E, Kaushal SS, Marshall V, McGrath BP, Nilon CH, Pouyat RV, Szlavecz K, Troy A, Warren P (2011) Urban ecological systems: foundations and a decade of progress. J Environ Manag 92(3):331-362

Pincetl S (2010) Implementing municipal tree planting: Los Angeles million-tree initiative. Environ Manag 45(2):227-238

Qian YG, Zhou WQ, Li WF, Han LJ (2015a) Understanding the dynamic of greenspace in the urbanized area of Beijing based on high resolution satellite images. Urban For Urban Green 14(1):39-47

Qian YG, Zhou WQ, Yu WJ, Pickett STA (2015b) Quantifying spatiotemporal pattern of urban greenspace: new insights from high resolution data. Landsc Ecol 30:1165-1173

Richards NA, Mallette JR, Simpson RJ, Macie EA (1984) Residential greenspace and vegetation in a mature city: Syracuse, New York. Urban Ecol 8(1-2):99-125

Smith RM, Gaston KJ, Warren PH, Thompson K (2005) Urban domestic gardens (V): relationships between land cover composition, housing and landscape. Landsc Ecol 20:235-253

Tan MH, Li XB, Xie H, Lu CH (2005) Urban land expansion and arable land loss in China-a case study of Beijing-TianjinHebei region. Land use policy 22:187-196

Tian YH, Jim CY, Wang HQ (2014a) Assessing the landscape and ecological quality of urban greenspaces in a compact city. Landsc Urban Plan 121:97-108

Tian YC, Yin K, Lu DS, Hua LZ, Zhao QJ, Wen MP (2014b) Examining land use and land cover spatiotemporal change and driving forces in Beijing from 1978 to 2010. Remote Sens 6(11):10593-10611

Turner MG, O’Neill RV, Gardner RH, Milne BT (1989) Effects of changing spatial scale on the analysis of landscape pattern. Landsc Ecol 3:153-162

Villeneuve PJ, Jerrett M, Su JG, Weichenthal S, Sandler DP (2018) Association of residential greenness with obesity and physical activity in a US cohort of women. Environ Res 160:372-384

Wang YP (2001) Urban housing reform and finance in China-a case study of Beijing. Urban Affairs Rev 36(5):620-645

Weng QH, Liu H, Liang B, Lu D (2008) The spatial variations of urban land surface temperatures: pertinent factors, zoning effect, and seasonal variability. IEEE J Sel Top Appl Earth Obs Remote Sens 1:154-166

Wu J (2004) Effects of changing scale on landscape pattern analysis: scaling relations. Landsc Ecol 19:125-138
Wu J (2007) Landscape ecology: pattern, process, scale and hierarchy, 2nd edn. Higher Education Press, Beijng

Wu Q, Li HQ, Wang RS, Paulussen J, He Y, Wang M, Wang $\mathrm{BH}$, Wang Z (2006) Monitoring and predicting land use change in Beijing using remote sensing and GIS. Landsc Urban Plan 78(4):322-333

Wu W, Zhao S, Zhu C, Jiang J (2015) A comparative study of urban expansion in Beijing, Tianjin and Shijiazhuang over the past three decades. Landsc Urban Plan 134:93-106

Yan JL, Zhou WQ, Han LJ, Qian YG (2018) Mapping vegetation functional types in urban areas with WorldView-2 imagery: integrating object-based classification with phenology. Urban For Urban Green 31:230-240

Yan JL, Zhou WQ, Jenerette GD (2019) Testing an energy exchange and microclimate cooling hypothesis for the effect of vegetation configuration on urban heat. Agric For Meteorol. https://doi.org/10.1016/j.agrformet.2019.107666

Yang J, Huang CH, Zhang ZY, Wang L (2014) The temporal trend of urban green coverage in major Chinese cities between 1990 and 2010. Urban For Urban Green 13(1):19-27

Yu WJ, Zhou WQ (2017) The spatiotemporal pattern of urban expansion in China: a comparison study of three urban megaregions. Remote Sens 9(1):45

Yuhendra Alimuddin I, Sumantyo JTS, Kuze H (2012) Assessment of pan-sharpening methods applied to image fusion of remotely sensed multi-band data. Int J Appl Earth Obs Geoinf 18:165-175

Zhang Z, Li N, Wang X, Liu F, Yang L (2016) A comparative study of urban expansion in Beijing, Tianjin and Tangshan from the 1970s to 2013. Remote Sens 8(6):496

Zhang B, Xie GD, Li N, Wang S (2015) Effect of urban green space changes on the role of rainwater runoff reduction in Beijing, China. Landsc Urban Plan 140:8-16

Zhao CJ, Fu GB, Liu XM, Fu F (2011) Urban planning indicators, morphology and climate indicators: a case study for a north-south transect of Beijing, China. Build Environ 46(5):1174-1183

Zheng SQ, Kahn ME (2008) Land and residential property markets in a booming economy: new evidence from Beijing. J Urban Econ 63:743-757

Zheng Z, Zhou WQ, Wang J, Hu XF, Qian YG (2017) Sixtyyear changes in residential landscapes in Beijing: a perspective from both the horizontal (2D) and vertical (3D) dimensions. Remote Sens 9(10):992

Zhou WQ, Huang GL, Cadenasso ML (2011) Does spatial configuration matter? Understanding the effects of land cover pattern on land surface temperature in urban landscapes. Landsc Urban Plan 102:54-63

Zhou WQ, Wang J, Cadenasso ML (2017) Effects of the spatial configuration of trees on urban heat mitigation: a comparative study. Remote Sens Environ 195:1-12

Zhou WQ, Wang J, Qian YG, Pickett STA, Li WF, Han LJ (2018) The rapid but "invisible" changes in urban greenspace: a comparative study of nine Chinese cities. Sci Total Environ 627:1572-1584

Publisher's Note Springer Nature remains neutral with regard to jurisdictional claims in published maps and institutional affiliations. 